Case Report

\title{
Presence of very good sds in a patient with residual hearing only at low frequencies: a case report
}

\author{
Abstract \\ Beside other tests, SDS test is one of the best tests in order to determine whether the test ear \\ is aidable or unaidable. Here, we will report a patient who had a very good SDS in spite of \\ residual hearing only at low frequencies.
}

Keywords: good sds, residual hearing, conductive hearing loss
Volume 3 Issue I - 2015

\author{
Alireza Bina, Shahriar Hourizadeh \\ Atieh Hospital,Audiology Clinic, Iran
}

Correspondence: Alireza Bina,Atieh Hospital,Audiology Clinic, Iran, Tel 8I7-666-2926,Email bina_alireza@yahoo.com

Received: January 27, 2015 | Published: August 07, 2015

\section{Introduction}

The patient is a 57years old woman who referred to our clinic for receiving hearing aid, having a history of middle ear infection and left ear Tympanoplasty. Audiometry had been performed in two other clinics, in both of which the results were similar (Figure 1). Audiometry was performed again on the patient (Figure 2). Unfortunately, the results of Audiogram 1 were incorrect. The patient suffered from mixed hearing loss in left ear, with severe conductive component, which was diagnosed by the other two clinics as sensorineural hearing loss.SDS test was performed in left year by masking level formula (presentation level - 20), and good SDS (88\%) was recorded as compared to the patient's severe to profound hearing loss. ${ }^{1}$

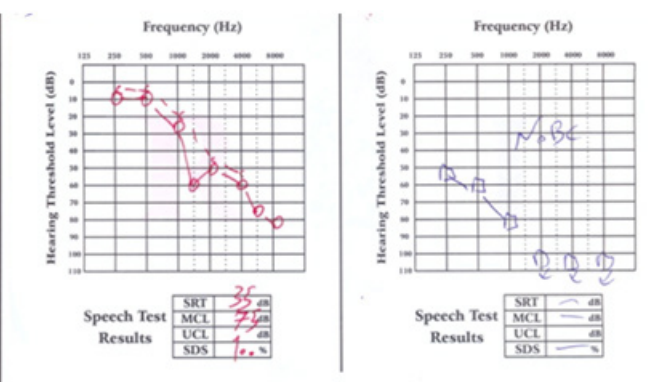

Figure I Audiogram.

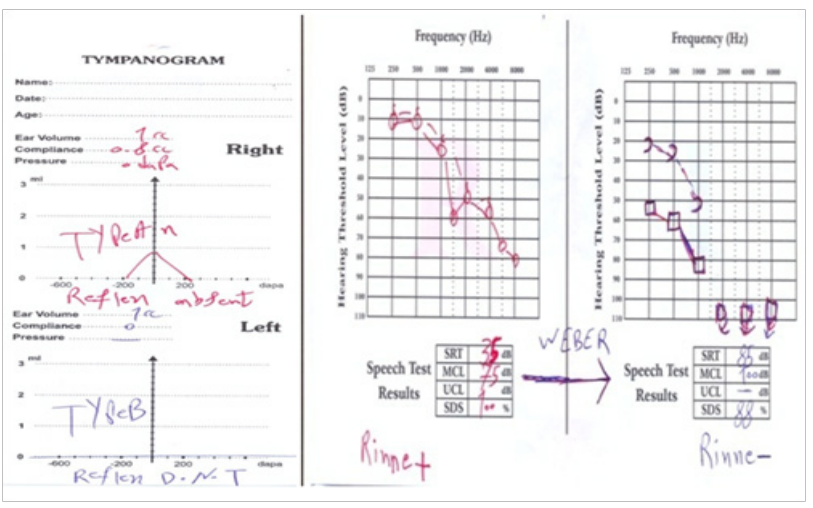

Figure 2 Audiogram and Tympanogram.
Diapasonic and audiometric Weber tests were lateralized towards left ear (affected ear) at most frequencies $(250 \mathrm{~Hz}, 500 \mathrm{~Hz}$ and $1 \mathrm{KHz})$, which indicates presence of conductive component in left ear and aid ability of left ear. The patient also suffered from sensorineural hearing loss, with SRT of $35 \mathrm{~dB}$ in right ear. The patient had a history of wearing a hearing aid for a short period unilaterally in right ear, which was fit by a clinic that previously performed audiometric test for the patient. But due to lack of speech recognition in noisy environments, the patient rejected the hearing aid. By performing the audiometric test again and finding good SDS in the patient's left ear, hearing aid was prescribed bilaterally.

The patient had much better speech recognition with two hearing aids than one, i.e. wearing the hearing aid only on right ear, even in quiet environment of the clinic. Localization of the patient with two hearing aids was better than one after wearing two hearing aids for one month, as stated by the patient. Two other clinics had incorrect left ear Audiometry (Figure 1) because the patient had residual hearing only at $250 \mathrm{~Hz}, 500 \mathrm{~Hz}$ and $1 \mathrm{KHz}$, and since such an audiogram is typical of sensorineural hearing loss, the condition was diagnosed as sensorineural hearing loss by mistake. In left ear Audiometry, bone conduction Audiometry has not been performed or the patient's good SDS was ignored. ${ }^{2}$

Diapasonic and audiometric Weber tests have not been performed. If the patient suffered from sensorineural hearing loss and did not have mixed hearing loss in left ear, Weber test was lateralized towards right ear instead of left ear, as observed in this patient.

\section{Conclusion}

Presence of good SDS in severe to profound hearing loss may be one of the reasons for conductive component in hearing loss. In severe to profound sensorineural hearing loss, typically the patient does not have good SDS.UCL and LDL tests are helpful to some extent. In this patient, there was no Hypoacusis in the left ear, whereas we often witness decreased dynamic range in severe to profound sensorineural hearing loss. Diapasonic and audiometric Weber tests are necessary and are of special importance beside other tests.

Supra segmental features of speech are at low frequencies. By prescribing a hearing aid for left ear, the patient obtains sentence recognition to a large extent. This also applied to speech recognition in quiet environments because the patient did not have residual hearing at frequencies higher than $1 \mathrm{KHz}$. Speech recognition in noisy environments will improve slightly in left ear and will not change 
remarkably due to lack of residual hearing, which has been told to the patient in counseling before prescription of hearing aid. Result of left ear Tympanometry was Type B with ECV of $1 \mathrm{cc}$ probably due to complications of surgery, because there was no tympanic membrane perforation in Otoscopy. Tympanometry of the patient's right ear was Type and acoustic reflex was absent in the right ear.

\section{Acknowledgments}

None.

\section{Conflicts of interest}

Author declars there are no conflicts of interest.

\section{Funding}

None.

\section{References}

1. Ross JR, Michael V, Holly HD Audiology: Diagnosis. ( $2^{\text {nd }}$ edn), Thieme publishers, Germany.

2. Jack K, Larry MW, Robert B, Linda H. Hand book of clinical audiology. (6 $6^{\text {th }}$ edn), Wolters kluwer, Lippincott, Williams \& Wilkins, USA. 2009. 